\title{
Lembranças da escola: sentidos históricos e questão indígena ${ }^{1}$
}

\author{
Memories of school: historical \\ meaningsand indigenous issues
}

Eunícia Fernandes*

\section{Resumo}

Com base em questionários respondidos por alunos e ex-alunos do curso de História da PUC-Rio, o artigo analisa conteúdos acumulados acerca da questão indígena no Brasil no grupo específico de professores ou aspirantes, identificando suportes para suas referências e perspectivas. Em diálogo com tal mapeamento, o artigo advoga o valor da escola e da experiência como lócus no processo de fundamentação de parâmetros como multivocalidade e descentramento, tidos como axiais na vida em uma sociedade que reconheça e respeite as diferenças.

Palavras-chave: experiência; descentramento; lembrança; escola; questão indígena.

\section{Abstract}

This article analyses how the knowledge about the various subjects of Indians and their History is accessed by an specific group of young history teachers and teachers to be. Using a questionnaire answered by current and former students of the History department of PUC-Rio, this work seeks to identify the fonts of their references and perspectives. In a dialog with the mapping, this work also defends the value of education and school and also of the experience as a locus in the process of building parameters such as multivocality and decentering, both being crucial for the society to be able to recognize and respect the differences.

Keywords: experience; decentering; memories; school; Indians.

Um dos pontos-chave para uma proposta dialógica é o saber ouvir. No caso de uma sala de aula é algo que se multiplica em muitos momentos, porém, logo no início do contato, na apresentação entre as partes, uma primeira conversa constrói para o professor um diagnóstico de seu contexto (e certamente também para o aluno...), permitindo que ele faça dialogar o conjunto de seus saberes com o dos estudantes e proponha, de modo específico, um caminho. Foi pensando assim que resolvi enfrentar a tensa questão do saber sobre os indígenas junto a historiadores e futuros historiadores, muitos dos quais já

\footnotetext{
* Pontifícia Universidade Católica do Rio de Janeiro (PUC-Rio). euniciaf@puc-rio.br
} 
professores atuantes ou que colocam o magistério como um horizonte em suas vidas: ouvir.

Este texto é, portanto, fruto de uma primeira conversa com alunos e ex-alunos do curso de História da PUC-Rio. ${ }^{2}$ Conversa criada a partir de um questionário que, como tal, formulou um contexto possível, simulacro desse contato acima citado. É fato que, por não sermos uma turma (apesar de muitos depoentes terem sido meus alunos), não teremos novas circunstâncias para adensar as perspectivas desenvolvidas no questionário, mas houve uma efetiva oportunidade de expressão coletiva e ela constituiu um quadro de referências que pode ser analisado e trouxe reflexões sobre a formação e a atuação docente (que podem desdobrar-se ainda mais).

Assim como na sala de aula, na sociedade há diálogos que constroem saberes, e pode-se dizer que as leis carregam esse princípio, pois imagina-se que elas sejam derivadas de aspirações e lutas sociais que foram validadas pelos representantes públicos. Porém, sabe-se o quanto esse princípio se esgarça no meio do caminho, seja pela pluralidade das aspirações - a sociedade não é una - como pela frágil representatividade em alguns Estados-nações. Desse modo, é preciso pensar no alcance do intercâmbio entre Estado e sociedade que sustenta as leis. No caso das leis 10.639/2003 e 11.645/2008, a meu ver, houve um significativo eco social que se consolidou por diferentes meios, desde a valorização da diversidade em âmbito mundial após a Segunda Guerra Mundial (cf. Fernandes, 2009; Gomes, 2013) até a organicidade do movimento negro e indígena nas Américas, passando pela Constituição de 1988, em âmbito nacional, apenas para citar alguns elementos.

Porém, esse eco social que me permite falar em diálogo não é extensivo e expõe, desde o início, limites claros. Um exemplo de limite - que tem consequências imediatas na efetividade legal - é que a defesa da obrigatoriedade do ensino de história e cultura afro-brasileira e indígena na escola não se configurou a partir de uma luta docente junto aos órgãos públicos: por mais que vários elementos sociais possam ser destacados como agentes ativos para a ação legislativa, a lei não foi demanda ou síntese elaborada pela "sociedade escolar", se podemos assim identificar um grupo de pleito. A lei, que define conteúdos e práticas para a escola, resultou muito mais de uma demanda de movimentos sociais negros e indígenas fora dos muros escolares. 
Em fins do século XX e início do XXI, uma visibilidade/consciência de alteridades e a exigência de tolerância foram ampliadas como discurso e, certamente, envolveram historiadores-professores-cidadãos que estavam se formando e atuando no período. Desse modo, imagino que em seu dia a dia - na leitura do jornal, na novela assistida na TV, no caminho para o trabalho, passando pela ocupação das ruas ou mesmo inaugurando o uso da internet - eles lidaram com o movimento negro e o indígena ou com temas que os envolvem diretamente, como a questão da terra no Brasil. Mas o leitor deve concordar que entre o partilhar de um cenário público e a exigência de ação específica no âmbito profissional há uma distância.

Participar da maior visibilidade de grupos historicamente marginalizados não necessariamente fez dos profissionais do magistério especialistas nas história e cultura desses grupos. Acredito que essa distância entre a nova obrigatoriedade e as condições para executá-la se fez sentir na morosidade ou ausência de estratégias para incorporação dos saberes sobre África, afrodescendentes e indígenas pela escola quando da determinação das leis 10.639/2003 e $11.645 / 2008$. Acredito que caso fosse uma demanda elaborada pela e na escola, o processo de elaboração da perspectiva seria simultaneamente genitor de ações para sua efetivação, o que faria a diferença em implementações mais céleres.

Mesmo que de forma superficial, é bom ter clareza dessa dinâmica histórica, pois sem identificação de contextos qualquer avaliação é muito limitada - mas não é esse o ponto que pretendo discutir aqui. Aliás, é bom indicar que em alguns lugares não houve morosidade ou fragilidade na implementação de projetos, pois já estavam como pauta escolar antes mesmo das demandas legais, viabilizando a promoção ou ampliação daqueles conteúdos exigidos. Interessante é saber que em algumas dessas escolas, com um corpo docente preparado e antenado com o mundo, as respostas dos alunos não foram as esperadas, gerando surpresa para alguns e mantendo hiatos cognitivos e sociais que a legislação pretendia e ainda pretende eliminar. ${ }^{3}$

Este artigo ambiciona, portanto, compartilhar um ouvir para, a partir dele, refletir junto sobre o porquê da inexistência de iniciativas ou do tatear delas para fazer cumprir as leis, bem como pensar o porquê dos entraves quando da apropriação por alunos de propostas que foram efetivadas. Esclareço ainda que, em função de meu interesse de pesquisa, apesar de a legislação se referir 
também ao ensino de História e Cultura da África e dos afro-brasileiros, as reflexões aqui apresentadas estão voltadas para a temática indígena incluída em 2008, alterando o texto inicial da lei 10.639/2003.

O que sabemos e pensamos acerca dos indígenas não deriva dos conhecimentos escolares nem se esgota neles, porém, acredito que ainda seja a escola o referencial fundamental dos conhecimentos tidos como verdadeiros para a maior parte da população. Lembremos que, por vezes, o livro didático é o único que existe em muitas residências e ele, tanto quanto os projetos e ações escolares, não tem garantido informações mínimas para que a população em geral - os cidadãos - conheça as histórias e experiências indígenas, garantindo não apenas a lei 11.645/2008, mas a própria Constituição.

Desse modo é que estabeleço a associação entre questão indígena e lembrança da escola, apontando tanto os silêncios de conteúdo - que não permitem, por exemplo, que os alunos conheçam a multietnicidade indígena - como as estereotipias que constroem uma visão desqualificadora, na qual os indígenas são apresentados como preguiçosos, incapazes, inferiores, despreparados etc. E não sejamos ingênuos: se a questão da terra é axial nas disputas políticas em nossa sociedade, a compreensão de seu valor para os indígenas depende justamente de um saber qualificado que não se encontra na escola, o que se ratifica nas pesquisas sobre conteúdos indígenas nos livros didáticos utilizados no século XX. ${ }^{4}$

Isso faz que os postulantes a professores de História cheguem, em média, à maioridade sem um conteúdo mínimo ou envolvimento com a questão indígena. Ela é marginal na vida da maior parte dos brasileiros, inclusive na vida de professores do Fundamental e Médio, pois a atual exigência legal para o currículo expõe a ausência na escola, e a fragilidade de seu cumprimento expõe o despreparo e desconhecimento de docentes. Pode-se mesmo fazer a triste blague de que esse saber só existe "salvo quando se é indígena", o que agrava as sensibilidades, pois se o que foi afirmado é que a questão indígena é marginal aos brasileiros, pode-se interpretar que os índios estão fora dessa realidade, ou seja, que eles não seriam brasileiros! E são, como são!

Como essa ausência de conteúdos é histórica, os docentes de História que estão atuando certamente tiveram poucas oportunidades de investir eles mesmos num aprendizado, pois como alunos também não obtiveram informações. Diante dessa observação, o desconhecimento (e possível insegurança) 
de atuais docentes para lidar com a exigência legal em sala de aula poderia ser explicada.

Mas... explicada apenas em parte e deixando de lado o que eu talvez considere o mais relevante. Explico. Como alunos do Fundamental e do Médio, tais professores não teriam tido a oportunidade de um maior esclarecimento sobre as histórias indígenas ou as histórias do contato, porém, com a realização do curso superior, poderíamos imaginar a supressão do problema, já que os candidatos a professores de História acessariam os conteúdos necessários para sua atuação.

Minha questão é exatamente esta: será mesmo que os conteúdos universitários seriam capazes de suprimir o problema? Um excelente curso superior apresenta o que é necessário para a atuação desse professor no espaço escolar? Para identificar o que estou chamando de "parte talvez mais relevante que está sendo deixada de lado" e pensar sobre isso com você, leitor, proponho que vejamos o questionário e suas respostas.

O questionário foi organizado em 5 partes: (a) identificação; (b) lembranças gerais; (c) lembrança história do Brasil; (d) lembrança índios do Brasil; (e) presente e futuro.

Na parte da identificação, o foco esteve no gênero, idade e formação escolar. Ainda que não sejam dados explorados aqui, localizar a variação de apreensão entre homens e mulheres ou entre escolas públicas e privadas estava no horizonte do inquérito. Nas lembranças gerais foi priorizada a relação do depoente com o espaço escolar, num processo de estímulo ao processo rememorativo e consolidação de valores, alimentando a inspiração e referências gerais que poderiam ser articuladas às específicas. Na terceira parte, apesar do título e algumas questões fecharem no tópico "história do Brasil", a maioria das perguntas promove uma aproximação sensorial sobre os recursos da aula de História - o livro, o professor - e algum diálogo com o mundo fora da escola - o cinema, por exemplo. A intenção era a de ativar diferentes mecanismos de memória que pudessem qualificar as respostas. Considerando que o depoente seguiu a sequência do questionário, ele chegaria à quarta parte desperto para detalhes do pretérito e, por isso, talvez mais apto a localizar referências pontuais sobre a temática indígena no material didático que utilizou, às vezes, muito tempo atrás. A última parte promove o salto do passado para o presente, sugerindo que o depoente articule seu "hoje" - estudante ou historiador 
formado, professor atuante ou na intenção de - e aqueles conteúdos já respondidos e outros mais que tenha acumulado acerca dos indígenas no Brasil. Nesta, há questões reflexivas tais como "Você se sente seguro, ou seja, com informações suficientes e substantivas, para falar sobre os índios no Brasil? Por quê?", fugindo de conteúdos universais e suscitando uma autoavaliação.

Foram trinta questionários respondidos por ex-alunos e alunos de diferentes períodos. Destes, a metade afirmou lembrar-se da escola regularmente e a outra metade afirmou lembrar-se às vezes, mas ninguém colocou a lembrança da escola como algo distante. Também houve certo equilíbrio na formação dos depoentes que frequentaram escolas públicas e particulares, havendo um número reduzido de três depoentes que teve sua escolaridade nos dois tipos. A maioria formou-se na cidade do Rio de Janeiro, mas cinco foram escolarizados em outros lugares: Niterói, Petrópolis, Teresópolis, Belo Horizonte e Estados Unidos/Brasília. O equilíbrio, entretanto, inexiste quando localizamos o gênero, pois o número de questionários respondidos por homens foi de dez e, por mulheres, de vinte.

A amizade foi o tema majoritariamente indicado como o que intensamente traz lembranças da escola, ainda que professores, quadro-negro, livros ou mesmo comida tenham sido apontados como "coisas que lembram a escola". No caso das disciplinas com maior afinidade, a "história" esteve onipresente, mas dividiu o interesse de modo muito aleatório com matemática, química, física, educação física, biologia, português e geografia, o que demonstra trajetórias e preferências bem distintas no conjunto de entrevistados. No caso das disciplinas com menor afinidade, não houve unanimidade, mas a "matemática" foi a mais indicada, dividindo-se com todas as outras tradicionais disciplinas escolares de modo também genérico, pois as citadas como disciplinas afins reapareceram na questão das "três matérias que não gostava”.

Nas lembranças gerais sobre a escola, a figura do professor ganha destaque pois quase todos têm o nome de um ou mais para citar. Junto aos nomes, apareceram várias histórias e, entre as mencionadas, apenas uma - de uma professora que espancava os alunos com uma régua de madeira (Depoente 26) - foi negativa. As referências trazem sempre o professor que sabe muito, aquele que é solidário com os alunos ou ainda o que reúne todas as qualidades, construindo uma imagem positivada desse papel. 
Lembro-me de dois professores que foram muito especiais pra mim: o primeiro é o Camilo de História, que foi, mais ou menos, o meu mentor de vestibular. E a outra foi a Fernanda, professora de química que, mesmo sabendo que eu odiava a matéria, sempre me chamava para participar das aulas a fim de que eu aprendesse mais e, quem sabe, começasse a gostar da matéria. (Depoente 11)

Imediatamente depois do tema professor, apresentava-se questão sobre a lembrança de livros especiais. Um respondente disse não se lembrar de nenhum, e seis disseram ler muitos ou poucos, sem fazer nenhuma indicação; entretanto, todos os outros tinham um ou mais títulos e autores com impressões precisas: algo de que gostou muito, algo que foi surpreendente, algo que foi tenso por ter sido obrigatório etc. A maioria das obras lembradas e classificadas como especiais foi de literatura, mas dois depoentes indicaram o livro didático como especial, um com a afirmativa - "Sim, até hoje tenho guardado A História da Riqueza do Homem que usei na 6a série ginasial" (Depoente 27) - expôs a permanência/atualização do valor atribuído no passado a uma obra de cunho histórico.

Quando direcionados para o livro didático, apenas um dos entrevistados disse não se lembrar dele, já a capa e as imagens foram os elementos que permaneceram mais vivos na memória dos entrevistados, quando comparados aos textos ou às atividades. Eu acreditei que o livro do Ensino Médio seria o mais lembrado, pela proximidade no contato, mas me equivoquei: os livros do Ensino Fundamental foram tão citados quanto os do Ensino Médio. E vale dizer de um detalhe interessante: na lembrança da dinâmica de uso do livro, entre as alternativas do professor dando aula, do depoente lendo o livro ou dele escrevendo no livro, a primeira - a que envolve diretamente o professor - teve vinte assinalações, ou seja, mesmo que o livro seja do aluno, que ele o leve para casa, o elo que se apresenta mais forte na memória é o do livro associado ao professor.

Quando indagados sobre algo inesquecível do livro didático, três não responderam, quatro disseram que não havia nada em especial, e todos os outros exibiram uma memória particular, pois se algumas imagens foram responsáveis pelas marcas nesses indivíduos, também o cheiro do álcool de apostilas ou a transformação na grafia das palavras foram dados que surgiram nas respostas. 
Sim. O livro era do sexto ano. Havia na capa a imagem de um índio com um disco de madeira em seu lábio inferior e, esta imagem me marcou muito. Tanto que muitos anos depois, enquanto professora de reforço escolar, recebi uma doação de livros e entre eles estava um exemplar do mesmo e, quase chorei quando o tive em minhas mãos. Muitas lembranças me vieram à mente. (Depoente 13)

A relação afetiva que os depoentes (em geral) estabeleciam/estabelecem com o livro didático se estende nas questões posteriores que comparam o que mais se gostava e o que não se gostava naquele material. Para o gostar, apesar de algumas abstenções de resposta, houve uma variedade de interesses como os quadros de curiosidades, os registros de documentos, as fotografias, as indicações de filmes e outros, reforçando a máxima de que "forma é conteúdo" e que, mesmo sem terem assinalado anteriormente como "especial", as explanações dessas questões exibem que aquilo que um professor descarta ou desconsidera pode ser justamente o que é retido pelo aluno.

Não me lembro de não gostar de algo específico do livro, mas lembro de achar que haviam várias sugestões de dinâmicas nos livros que nunca foram utilizadas pelos professores. Admito que achava que as dinâmicas poderiam ser divertidas. (Depoente 6)

O afeto, nesse caso, se estabeleceu a despeito do professor e, na estatística, se apresentou no fato de muitas pessoas "não lembrarem" de coisas negativas do livro didático (em trinta respostas, foram dez, existindo seis abstenções), ou seja, as lembranças são boas. Para aqueles que efetivamente não gostavam de algo no livro, os famosos "questionários" - articulados às atividades repetitivas ou ditas maçantes - foram os mais citados, seguidos da pobreza nos recursos visuais e de críticas isoladas, como letra miúda e texto muito resumido.

Houve, no jogo do lembrar/esquecer, uma interessante conjugação. Lembramos de coisas boas e de coisas ruins, assim, houve quem lembrasse negativamente dos questionários, uma ação em que o aluno lê ou escreve no livro. Mas essa não foi a lembrança mais recorrente, pois na questão anterior, quando foram indagados sobre o uso do livro, o maior número de respostas recaiu sobre o livro sendo usado pelo professor como a memória mais viva. Sendo assim, o que aqui aparece como negativo - o questionário - é, no 
conjunto das recordações, algo marginal, o que fortalece a interpretação sobre $o$ afeto na experiência de uso do livro.

Na terceira parte do questionário, referente à história do Brasil, há conexões significativas entre lembrança e esquecimento que acredito tenham escapado aos próprios depoentes. A primeira questão indaga sobre os três conteúdos mais fáceis de lembrar do livro de história; a segunda, sobre os três conteúdos que o depoente mais gostava, e a terceira, se o depoente lembra do tema "indígena" no livro.

A primeira articulação interessante é que os assuntos mais "fáceis" de lembrar, na maior parte das vezes, não eram os da predileção do depoente e que, dos 12 que atestaram não se lembrar da temática indígena, 11(!) responderam questões posteriores que detalhavam as imagens de indígenas nos livros didáticos bem como os textos desses materiais. Pesquisas poderiam aprofundar as composições "lembro mas não gosto" e "gosto e não lembro", bem como poderíamos nos aproximar das expressões da memória e dos usos do passado, especificamente do passado escolar que se camufla no cotidiano dos agentes e interfere nas decisões e posicionamentos sem que o identifiquemos.

Para este texto, cabe observar que o tema "descobrimento do Brasil" / “colonização" apareceu como "mais fácil de lembrar" para 18 depoentes, porém como predileção de apenas seis. É também significativo ver que quatro dos depoentes que indicaram o tema do descobrimento / colonização do Brasil como dos mais fáceis de lembrar também estão entre aqueles que disseram não lembrar pontualmente o que era apresentado no livro didático sobre os indígenas no Brasil, mas que acabaram por responder questões mais detalhadas na temática.

O número de 18 respostas é também um dado importante quando casado com a última questão do bloco: a pergunta procurou localizar a temporalidade dos conteúdos acerca dos indígenas nos livros didáticos utilizados (período colonial ou século XX) e, simultaneamente, se apresentavam uma dinâmica de tutela ou de autonomia (catequese/missionação ou organização indígena). Absolutamente todos os depoentes indicaram que a catequese e missionação colonial foram a base dos textos dos livros didáticos que utilizaram e, se nove indicaram conteúdos sobre catequese no século XX, todos os entrevistados consideraram inexistente a referência sobre os movimentos indígenas no livro didático. Ou seja, se o momento do descobrimento/colonização está entre os 
mais “fáceis de lembrar", ele atinge diretamente a percepção da temática indígena como pretérita, e se o conteúdo é apenas o da ação colonizadora e não o do movimento indígena, constrói-se uma perspectiva de ingenuidade, fragilidade e incapacidade desses povos.

Para fechar os dados deste bloco: no detalhamento das imagens do livro didático, pode-se observar a construção de uma iconosfera (Meneses, 2003) alheia às realidades plurais (de ontem e de hoje) dos povos indígenas. Na sondagem sobre elas, o uso de "pinturas de época" para retratar os indígenas foi majoritário e eles apareciam, segundo os entrevistados, pintados sem roupa, como habitantes de florestas (nenhum citou a cidade) e em ações ritualísticas ou de caça, nunca numa atividade contemporânea, como na escola ou usando um computador, isso mesmo nos livros que foram identificados como usuários de fotografias ou desenhos feitos especialmente para a edição. As palavras dos depoentes materializam a perspectiva que foi construída com tais imagens. Diante da questão "Com a lembrança que você tem dos SEUS livros o que você sabe sobre os indígenas do Brasil?" encontramos as seguintes respostas:

Eles viveram na floresta, hoje existem poucos que ainda vivem lá, não fazem parte do presente da sociedade brasileira. (Depoente 1)

Povos Selvagens e que precisam do contato com o homem branco para se tornarem mais desenvolvidos. (Depoente 3)

Os índios que chegaram até a mim através dos livros escolares eram criaturas preguiçosas, ingênuas, conformistas. Que se encantaram num primeiro momento com o homem branco, mas depois foram dizimados pelos mesmos. (Depoente 28)

Se eu considerar o conhecimento que tenho sobre os índios do Brasil com base, apenas, nos livros didáticos de história que tive do final da década de 80 ao longo da década de 90 do século XX, diria que o saber que tenho sobre os índios do Brasil é pouco e marcado por estereótipos. (Depoente 23)

Com as lembranças dos livros didáticos não sei praticamente nada. Aprendi mais tendo que dar aula do assunto em pré-vestibular. (Depoente 13)

A questão foi retomada no início do bloco seguinte, numa outra formulação - "Com a lembrança que tem das informações textuais dos seus livros didáticos de História, o que você sabe sobre os índios do Brasil?”. Repetirei depoentes (1 e 13) para que o leitor observe como vão se somando dados 
negativos para uma compreensão da temática indígena e trarei outros (Depoentes 7 e 21) para expor o alcance do problema:

Os indígenas eram serem ingênuos que foram catequizados e enganados pelo colonizador que só queria suas terras e seus bens valiosos. (Depoente 1)

Poderia dizer que, os índios nunca tiveram uma história própria, que foi um povo selvagem e atrasado, que precisava ser salvo, educado e ensinado pelos mais evoluídos, que foi um povo que viveu no passado e por lá ficou. (Depoente 13)

A lembrança que tenho é de que o Índio tinha um papel secundário nas informações passadas. (Depoente 7)

Foram um povo importante para a construção da identidade brasileira hoje, mas foram explorados no começo da colonização, "defendidos" pelos jesuítas, mortos em grande escala pelos portugueses e isso caracterizou a chegada dos europeus na América. (Depoente 21$)^{5}$

Pelo que foi descrito até aqui, o afeto que tais alunos depositaram em seus livros escolares e professores pode ser portador de uma lembrança que, em outras condições, talvez se tornasse esquecimento. É preciso, porém, trazer algumas problematizações para que não sejamos ingênuos na incorporação desses discursos.

O primeiro ponto a destacar é que a memória não é o que ocorreu, mas uma construção seletiva sobre a experiência. Esses respondentes podem ter guardado amigos e livros para consulta, deixando seus depoimentos mais próximos daquilo que acreditam ter vivido, mas, sem retirar-lhes qualquer verdade, sabem bem que suas impressões são agenciadas pelas pessoas que são hoje. Desse modo, por exemplo, lemos a positivação do professor, na articulação de que eles - antigos alunos - também se tornaram pessoas desejosas de atuarem como tais.

O segundo é que, como memória ou como vivência, as avaliações que tais alunos tinham e têm sobre a escola não derivam apenas da escola, assim como as informações (e desinformações) sobre os indígenas. Tudo o que os espaços escolares forneceram dialogava com a vida de cada um deles, e não podemos deixar escapar que o silêncio de um livro didático talvez estivesse compondo com expressões em família como "programa de índio", usual e que indica algo negativo, tendo até mesmo denominado um programa televisivo. 
Mas se trabalharmos as informações com a cautela da pesquisa e considerarmos o coletivo dessas lembranças, estaremos de fato diante de cenário desalentador. Cenário minimizado pela experiência universitária que, em função da formação acadêmica ou profissional, exigiu mais deles e gerou uma qualificação atestada por todos. Mas cenário incompleto, para o bem e para o mal, pois não podemos esquecer que o processo de ampliação de saberes fomentado pela vivência universitária não dá conta dos outros que vivem a escola. Sim, o questionário focou um grupo específico - historiadores formados ou em formação, professores atuantes ou que colocam o magistério como uma meta -, e professores de outras áreas que também atuam no espaço escolar (como a área de linguagens, tão importante para a temática indígena) não foram investigados.

Ampliação tida como limitada também porque dentro desse grupo em especial e após o aprimoramento de dados, as duas últimas questões da investigação exibiram ainda um alto grau de desconhecimento: ao serem indagados sobre o teor da lei 11.645/2008, dez disseram desconhecê-la totalmente e três disseram não saber, apesar de suporem ser a lei da obrigatoriedade de ensino de história e cultura indígena. E, mesmo entre os que sabiam o teor da lei, a ação diante dela se mostra frágil quando indagados "quais autores, livros, sites ou outros suportes procurar para buscar informações atualizadas e confiáveis sobre a vida atual dos índios no Brasil?", 18 depoentes assumem desconhecer onde encontrariam tais recursos.

Às vezes nossos alunos lançam questões pertinentes ou instigantes que o tempo da aula não nos permite aproveitar por completo. Aqui vivo o mesmo. As observações dos depoentes dão margens a reflexões que o artigo não terá como desenvolver, mas acredito que possa refletir sobre peculiaridades do espaço escolar que não só o distinguem do acadêmico, bem como exigem uma atenção para as relações entre a memória e a história no desejo de qualificar a produção de sentido histórico. Acredito que tais ideias possam esclarecer o que mencionei ser relevante e que fica de lado - quando se acredita ser suficiente a formação universitária na qualificação para o trabalho com a temática indígena na escola -, estimulando não só um cuidado no pensar a formação de professores mas um necessário fluxo entre "formação escolar" e "formação de professores". 
O que de imediato podemos acionar sobre o questionário está, de fato, acessível independentemente dele, mas como algo tão tangencial e naturalizado em nossas realidades que passa despercebido mesmo sendo de grande importância, especialmente para o tema que persigo: o rarefeito diálogo entre conhecimento e sociedade. Rarefação modelada pela universidade que, em prol do científico, muitas vezes desatou os nós com o mundo, e que, quando não considera o saber como algo construído com, enseja a repetição de verdades do livro ou do professor/autoridade. A indicação no questionário de esquecimentos ou de lembranças ocas (como os depoentes que disseram ter lido muitos ou poucos livros sem nomearem nenhum) expõe os hiatos que podem se construir (e se constroem) entre o mundo escolar e o mundo fora da escola, por mais que saibamos que a escola faz parte do mundo. Hiatos que se estabeleceram na ausência do diálogo e que, se num primeiro momento podem fragilizar o conteúdo escolar porque não o adensam e problematizam com a vida que existe fora da escola e que ali está presente em cada um dos alunos, malevolamente podem se repetir no rumo contrário, com alunos e ex-alunos sem carregar para vida aquilo que pulsa na escola.

Vazios. O que lembramos e acionamos conscientemente do conteúdo escolar em nossas vidas adultas?

Não falo de professores com bolas de cristal capazes de prever conteúdos "úteis" em 30 anos para seus diferentes alunos, isso é de uma tolice indizível, não apenas pela previsão mas pela ideia mesma de utilidade. Aponto para a construção de sentido no momento da produção do conhecimento, pois um sentido incorporado é memorável, ele passa a fazer parte do indivíduo, do repertório de que dispõe para pensar e agir no mundo. Destaco que não é o conteúdo em si, pode ser história como pode ser matemática, mas uma construção capaz de produzir conexões e significado para quem a vivencia. A isso acrescento que acredito que a internalização do dado na elaboração desse repertório está na sua articulação com o contexto do sujeito, na sua potencialidade de apreensão e agência em seu tempo e espaço. Internalizado, o conteúdo pode até não estar em evidência o tempo todo, mas será acionado pelo sujeito diante de novos contextos que o provoquem.

Então, um primeiro alerta que podemos ter no processo de formação de professores é a necessária reflexão sobre o diálogo ou seu oposto, os hiatos que derivam da ausência de diálogo. Pontuar que a premissa de um conteúdo 
significativo - notadamente em história - está presente na suposição da escola como formadora de cidadãos, ou seja, na ideia do papel da escola em prover informações e condições para que o aluno se torne capaz de articular os conhecimentos escolares fora do espaço escolar e quando deixar de ser aluno.

O conteúdo de história para a escola nitidamente aqui não se confunde com a proposição acadêmica. Ele não prevê a formação de profissionais da pesquisa universitária e incorpora variáveis e compromissos que envolvem direta e imediatamente a sociedade, a comunidade, o grupo com o qual trabalha, dialogando com as questões de suas memórias, nas relações de afeto e identidade que promovem e na continuidade que carregam. Chegar à diferença de objetivos entre o saber escolar e o saber acadêmico ${ }^{6}$ permite ratificar que a produção de sentido histórico não é exclusividade da ciência histórica. Há interpretação das ações do homem no tempo além da história como ciência, e se ela se tornou um modelo oficial não devemos esquecer a historicidade desse fato. ${ }^{7}$

O hiato, que parece óbvio para os estudantes que questionam por que aprenderem certos conteúdos que se lhe aparecem como "inúteis" e para adultos que vivenciaram a perda de muitos deles no meio do caminho, nem sempre é crivo de professores quando da seleção dos conteúdos e das atividades a serem desenvolvidas na aula de história. Cobertos pelo imediatismo de diferentes expectativas tais como a de pais que desconhecem os entremeios da educação e aguardam o "sucesso" de seus filhos medidos em números - notas na escola e cifras no banco -; como as de programas governamentais que homogeneízam padrões; cobrados pelas instituições e pela pressão financeira; muitas vezes sem recursos materiais ou humanos para o enfrentamento de mudanças, os professores de história se percebem reproduzindo cronologias e eventos sem uma prévia escolha, sem a reflexão de serem eles os mais adequados à formação de seus alunos no contexto específico em que se encontram, de serem aqueles os dados relevantes à vida dos estudantes para que consigam lembrar e operar com eles em suas vidas futuras, pensando historicamente.

O transcorrer da vida é limite inexorável, havendo a decalagem entre o hoje na escola e o amanhã fora dela. Considerar a necessidade de lidar sempre com novos contextos, portanto, deveria ser um balizamento importante e presente na seleção dos conteúdos e das metodologias do Ensino de História. Tal preocupação, acredito, otimizaria competências e habilidades e diminuiria 
uma visão apequenada do saber que delimita conteúdos tidos como "inúteis", pois os sentidos estariam resguardados no processo da aprendizagem.

Essa decalagem temporal permite enfatizar a especificidade do espaço escolar e a relação entre memória e história. Enquanto o acadêmico exige um refinamento e distinção entre as duas para um qualificado uso, essa não é uma exigência para o espaço escolar. Vejo como possível e positivo que um professor trabalhe com tal distinção na escola, mas ela não é imperiosa e, além disso, as estratégias, dinâmicas e procedimentos escolares - quando contextualizados e contextualizantes - demandam um uso intenso de referências de memória individual e coletiva, o que não ocorre isolado da reflexão histórica. Há, portanto, um uso mais aproximado entre as duas no propósito de prover significação no momento da aprendizagem e de capacitação de operacionalidade futura. Assume-se a complexidade de acionar conteúdos e racionalidade crítica, mas não apenas, pois, para viabilizar uma operação crítica numa próxima experiência do aluno, seria importante fazer isso envolto num processo de internalização que articule os sentidos e acione a dinâmica afetivo-identitária que é constituída na memória, pois é através desses mecanismos que se constrói uma significação.

Há outra questão oculta nesse hiato espaçotemporal entre "escola" e "fora da escola", e tem igual ou maior valor. Foi destacado o hiato, aquilo que ficou como vácuo, interrupção, desligamento entre a escola e o mundo, quase como se ela não fizesse parte dele. Mas há também o inverso. Há entranhas da escola que se agarram nos sujeitos sem que eles vejam, percebam, sintam. São conteúdos que foram tão bem moldados ao sujeito que parecem ter nascido com ele, passam a ser acionados mecanicamente, sem nenhuma reflexão. São conteúdos que foram internalizados como verdades, sem racionalidade crítica e, portanto, dificilmente são reconhecidos como conteúdos apreendidos no espaço escolar por aqueles que os carregam, não podendo, portanto, ser compreendidos ou combatidos.

Ou seja, quando pensamos na formação docente, deveríamos valorar as seleções de conteúdos e metodologias, considerando que as ações efetivadas no espaço escolar podem cristalizar-se como verdades incontestes de maneira que os agentes sequer reconheçam sua origem e não mais tenham autonomia, repetindo sem reflexão ou sentido modos de ver e de viver. Nesse caso, seria obrigatório ao professor (e à formação de professores de história) estar ciente 
e operar com tal pressuposto, ao custo do outro lado da moeda, pois as experiências sensíveis ocorrem, as lembranças da escola acontecem e direcionam valores e ações futuras independentemente do cuidado e atenção do professor, para o bem e para o mal.

Exemplar dessa ação oculta é o fato de a maior parte dos entrevistados desconhecer onde buscar informações confiáveis sobre questões indígenas, já que a formação do historiador supõe a qualificação no processo de pesquisa. O que isso significa? Nas escolhas atuais desses profissionais, mesmo com toda a crítica que possam fazer sobre a formação frágil que tiveram na escola, eles a reproduzem, pois continuam secundando esse conteúdo no conjunto dos investimentos que fazem para serem professores. Desse modo, mantiveram-se os vínculos profundos que se estabeleceram e criaram normatividades sem sequer serem reconhecidos.

O que fica patente, portanto, é que o conteúdo histórico não pode ser descolado de sua metodologia, pois a forma - capaz de prover sentido e ser memorável - é também conteúdo. A consideração, a análise e o planejamento dos procedimentos, numa valoração da experiência dos alunos, são imperativos.

O valor da experiência, do envolvimento pessoal no processo de efetiva reflexão e incorporação de conteúdos é outra evidência do questionário. Os depoentes foram unânimes em dizer que o período no qual acumularam mais informações sobre a temática indígena foi o da graduação, porém, o modo como o fizeram não necessariamente estava articulado diretamente a ela. Ninguém mencionou uma disciplina específica na graduação, alguns disseram da participação em pesquisa de iniciação científica, mas essa opção estava ao lado daqueles que disseram ter aprendido sobre os indígenas nos jornais, no cinema, no trabalho em pré-vestibular comunitário e em revista de história, no estudo para concurso público etc.

O termo "aprendizado experiencial" aparece recentemente na psicologia educacional, mas a valoração da experiência como suporte para a compreensão é anterior e está presente na proposta construtivista e no método Paulo Freire, no campo pedagógico estrito senso, mas também no materialismo histórico de Marx e na história social do século XX, no campo historiográfico. Deixando ao leitor que ancore sua matriz, o que temos no questionário? Os respondentes são pessoas que estão num momento particular da vida, pois são todos adultos 
que assumiram uma diretriz profissional e, em muitos casos, pessoas que buscam sua autonomia financeira aliada à realização pessoal, representadas na saída da casa dos pais e na formação de uma família, entre outros aspectos. Sendo assim, possuem uma responsabilidade sobre o seu fazer diferenciada, quando os comparamos com crianças e adolescentes: a simples leitura do jornal e a menção de aprendizado através dela, demonstra uma possibilidade financeira e um comprometimento social inexistente em crianças e incomum em adolescentes.

Essa responsabilidade ou consciência das escolhas está presente nos exemplos dos entrevistados, na informação do como/quando acessaram os conteúdos sobre os indígenas no período universitário. A leitura do jornal ou a ida ao cinema são experiências do cotidiano que aparecem carregadas de novos sentidos, pois no contexto universitário podem servir à busca do emprego ou ao acesso a bens culturais que diferenciam o aluno; assim, mesmo que tenham iniciado como entretenimento, foram acionadas pelos depoentes como fontes de conhecimento válidas e que qualificaram sua bagagem escolar, ou seja, eram conteúdos adicionais que os depoentes interpretaram e somaram àqueles que já possuíam.

Na iniciação científica a dimensão experiencial talvez fique mais nítida porque sistematizada para a construção do conhecimento, sendo reconhecida tanto pelos orientadores como pelos orientandos como um divisor de águas na trajetória do estudante, um momento intenso de aprendizados que o distinguem de seus colegas. Do mesmo modo, o trabalho em pré-vestibulares - no caso da PUC-Rio - marca um momento de autoconhecimento e autonomia do graduando em história, pois é trabalho voluntário que só existe com compromisso e integralidade do graduando. A busca pelo concurso público ou o trabalho efetivo numa revista de história são também alternativas nas quais se identifica a entrega pessoal, pois são exemplos da aspiração ou da realização de colocações profissionais, da possibilidade de manter-se e seguir a sua própria vida e que exigem o esforço além da própria graduação. Desse modo, os conteúdos apreendidos em tais contextos carregam em si as cargas afetivas, morais e psicológicas que o viver traz para cada um. Não é estudar um capítulo para o teste da semana que vem, como pode (ou não) fazer um aluno de $7^{\circ}$ ano, mas a consciência do investimento pessoal na própria vida, aquilo que a fará ou a faz possível. 
O que desejo destacar é o grau de interesse e envolvimento manifesto pelos depoentes quando do acesso aos conteúdos sobre os indígenas. Eles foram realizados em diálogo com o presente e com as necessidades do entrevistado, um conteúdo que teve de ser acionado de imediato na pesquisa de IC, no texto que seria escrito para a revista, na aula que seria ministrada. Um investimento que pode ter tido a assessoria de um orientador (ou não), mas foi resultado de uma busca pessoal, de um esforço de levantamento e leitura, de localização das pertinências ao seu interesse e dos dados tangenciais no desenvolvimento de um posicionamento. $\mathrm{O}$ aluno de IC deseja aprender a pesquisar e manter a bolsa de estudos, além de ter colegas com os quais pode ser comparado, enfim, há fantasmas que o assombram e exigem seu esforço. O pesquisador da revista terá seu material revisto por outros colegas, historiadores ou jornalistas, será avaliado por seu supervisor e poderá permanecer ou não no emprego. O professor de pré-vestibular enfrentará o receio de não saber responder a seus alunos, pessoas das quais se aproxima e afeiçoa, nas quais reconhece a trajetória difícil, e passa a desejar fazer sempre o melhor. Os conteúdos produzidos nessas situações - fossem sobre os indígenas ou não - ganharam em significado e força pela dimensão experiencial, da reflexão proveniente de uma prática que dialoga com uma realidade e exige um investimento pessoal, tornando-se, portanto, memoráveis.

Como um processo dialético e ininterrupto no qual, mediante a interação com outras pessoas e com o ambiente, as potencialidades do indivíduo são estimuladas e colocadas em ação (Pimentel, 2007), os exemplos dos depoentes deixam claro o que foi mencionado antes: não se espera que cada aula de história seja um evento memorável (creio que nem alunos nem professor suportariam), mas a reflexão sobre como trabalhar os conteúdos é tão importante quanto os conteúdos mesmos.

A leitura do jornal diário, o trabalho ou mesmo o lazer (como no caso do cinema) foram mencionados como tempo-espaço de acúmulo de referências sobre os indígenas no período da universidade. Esse dado não somente deu subsídio à dimensão experiencial a que me reportei antes, mas significa também dizer que o processo de produção de conhecimento e avaliação sobre ele não ocorre com exclusividade nos espaços escolares e acadêmicos. Longe disso. O ser humano está em permanente processo de contato com o mundo, contato 
que o envolve e o demanda a agir, vetorizando saberes que são constituídos fora dos espaços escolares e acadêmicos.

Concordo com Rüsen quando supõe que os sentidos da experiência histórica não estão confinados na escola e na academia e começam a se processar no indivíduo antes mesmo que ele esteja em um desses espaços. As orientações do agir no tempo, o sentido que define as escolhas humanas estão se constituindo permanentemente, sendo uma ação inerente ao ser humano e não um domínio da disciplina História (Subrahmanyan, 2001). Entretanto, isso que, de modo sensível, todos sabemos porque nunca deixamos de levar conosco nossa bagagem, parece por vezes obliterado no universo escolar, cabe portanto lembrar que a escola não é nem exclusiva nem onipotente na formação dos indivíduos. Os conteúdos históricos estão ancorados em multifacetadas e fragmentadas experiências, assim como as consciências de si e do mundo que se podem produzir a partir deles e com eles.

De modo pragmático, o que é uma escola que não dialoga com esse coletivo que está além dela, materializado em cada aluno e em cada turma? Os alunos não são folhas em branco, e a possibilidade de ação efetiva/positiva da escola em suas metas depende de sua capacidade de conhecer e dialogar com as outras fontes de produção de saber. Mais, a escola não pode esquecer que tais saberes constituídos fora ou a despeito do espaço escolar nem sempre estabelecem conexões de entrosamento com aqueles que são ou querem ser constituídos por ela.

Vale aqui a retomada do caso do Centro Pedagógico da UFMG: depois de grande investimento com os alunos do primeiro ciclo do Ensino Fundamental, a visita de grupos indígenas redundou em perguntas extremamente tradicionais e estereotipadas, tais como se eles comiam gente e se eles poderiam continuar sendo índios se estavam vestidos. A manifesta surpresa da escola e dos professores engajados no projeto com a reação dos alunos evidencia simultaneamente o grande envolvimento deles naquilo que acreditavam fazer e também a força do que extrapola a escola na alimentação de referências e valores junto aos seus alunos. A vida acontece em todo lugar. Não é porque o aluno (e o professor) ingressou nos muros da escola que se compartimentaram as referências, e, a meu critério, nem deveria ser assim, afinal o saber sobre o mundo (que se aprende na escola) deve ter o mundo no saber. 
Para desenvolver considerações sobre a temática indígena na dinâmica das lembranças escolares e destacar o valor da formação escolar e do fluxo entre esta e a formação docente (ponto que considero relevante, mas desconsiderado quando da suposição da suficiência universitária) na qualificação para a agência docente no tema, retomo os alertas anteriores - derivados do questionário - para reuni-los em duas chaves de problematização: o contexto como produção de sentido histórico e a dimensão experiencial como articulação entre memória e história.

Os hiatos entre a escola e o mundo fora dela foram o primeiro alerta assinalado, e creio ter sido facilmente acolhido pelo leitor porque destaquei a temporalidade: o hoje da escola em contraponto ao amanhã desconhecido fora dela. Mas os hiatos definitivamente não existem apenas no eixo temporal, e o último alerta, aquele que realça o fato de a produção do conhecimento e da orientação na vida não ocorrerem exclusivamente em espaços escolares e acadêmicos, pode ser outra face deste mesmo ponto: há hiatos sincrônicos. Pode haver - e na maior parte das vezes há - rupturas de sentido entre o que os alunos vivem em suas casas, o que assistem na TV, o que escutam nas ruas e aquilo que é prescrito na e pela escola.

Sendo assim, os hiatos me ajudam a defender que nenhum conteúdo - no caso, história e cultura indígena - pode ser trabalhado sem uma efetiva contextualização, ao risco de se tornar uma referência irrefletida e dogmática (apenas reproduzir o que o professor diz, sem conexão com o mundo que se vive) ou um caótico e conflituoso quadro, difícil ou incapaz de constituir para o sujeito um posicionamento. A produção de sentido histórico na sala de aula, portanto, implica o reconhecimento compartilhado entre alunos e professores de seus dados e pressupostos, num diálogo capaz de incorporar o mundo que está fora da escola mas que se materializa em cada um deles, e promover - nas exigências da lei 11.645/2008 - o saber e a valorização da diferença.

Acredito que a oportunidade do ouvir das múltiplas vozes e do enfrentamento da diversidade num propósito coletivo permite a internalização substantiva de conteúdos pontuais, pois ao depararmos com a alteridade, com o que nos confronta, melhor conhecemos e elaboramos a nós mesmos, num autoconhecimento e afirmação intersubjetiva. ${ }^{8}$ Mas não é apenas isso. A oportunidade do enfrentamento da multivocalidade permite a internalização do processo no qual a internalização de conteúdo se realizou, constituindo o 
conhecer como algo vivo, dialógico e, portanto, necessariamente incompleto. A experiência do enfrentamento da pluralidade das vozes é, ela mesma, formativa e como tal alimenta os indivíduos em suas posteriores experiências.

O que retenho é que a ação contextualizadora é capaz de produzir sentido no momento em que a aula de história ocorre, mas a ultrapassa, garantindo a atualização do procedimento contextualizador diante das novas realidades. Os sentidos históricos produzidos na sala de aula não serão os mesmos nos 30 anos depois, fora dela, mas os indivíduos serão capazes de produzir uma orientação para si nas novas realidades e, certamente, para isso utilizarão os referenciais daquela experiência pretérita para fazê-lo. Uma obra aberta que se consolida em cada novo momento.

Os conteúdos apreendidos na escola, que apenas parecem esquecidos mas permanecem informando as ações mais cotidianas e mecânicas dos sujeitos, foram o segundo alerta que o questionário permitiu. Aqui ele se une àquele que valora a experiência como caminho para reflexão e incorporação de conteúdos. A união entre os dois pontos ou alertas é que eles estão alicerçados em bases que extrapolam a racionalidade crítica.

A aprendizagem experiencial de Kolb supõe o seguinte fluxograma: (1) a vivência concreta; (2) a observação reflexiva sobre a experiência; (3) a conceptualização abstrata em que se gera uma conclusão/aprendizado, e (4) a experimentação ativa, na qual se planeja e se utiliza o aprendizado de modo cônscio. Refletir a partir da prática, como já mencionei antes, não é bem uma novidade, e esse esquema - ainda que potente para certas cogitações/transformações no espaço escolar - silencia sobre o que transborda o racional, já que se detém na conceptualização. Sua proposição pode dar início a perspectivas, mas limita-se ao desconsiderar o que não é racional mas é humano e está presente em toda e qualquer experiência, como a sensibilidade.

Há, em nós, segredos que desconhecemos. Um cheiro de café, uma música no rádio, um cafuné de avó podem ser teletransportadores imediatos e descontrolados que invadem nosso instante sem que deles tomemos conhecimento prévio: nos arrebatam a outros tempos e lugares e nos convidam a uma diferente sensação (às vezes boa, às vezes não) de misturarmos o hoje com aquele outro que fomos. Essas lembranças marcam a nossa trajetória, valoram nossa vida e direcionam nossas escolhas junto às nossas decisões racionais e críticas. A citada experiência do depoente 13 - que começou a chorar quando 
encontrou, nos livros que recebeu de doação, aquele no qual havia estudado - está entre essas, pois ele se lembrou do detalhe do adorno indígena que aparecia na capa. A imagem indígena não foi acessada para dar conta de um conhecimento sobre a temática, mas a emoção que revestiu sua experiência escolar permitiu o acesso ao dado.

Não é que a memória e a sensibilidade não sejam atuantes na experiência universitária, mas elas não são procedimentos usuais no processo de construção do conhecimento. Elas não são metodologias na construção de um pensamento e de um sentido histórico, pois a universidade se apresenta como lugar do discurso da ciência e, como tal, apartada da sensibilidade. A antes manifesta distinção entre saber escolar e acadêmico aqui se reforça, sempre ratificando que a produção de sentido histórico não é exclusividade da ciência histórica, legitimando, portanto, as alternativas de produção de sentido escolares.

Coloco a questão: diante da diferença de objetivos e procedimentos, como delegar exclusivamente à universidade uma formação de qualidade para a atuação diante da lei 11.645/2008? Como enfrentar com qualidade a singularidade do espaço escolar que lida com variáveis que extrapolam o crivo científico se, além de delegar à universidade o "suprir" de informações sobre a temática indígena, a maior parte dos universitários chegou à maioridade com produções de sentido deslocadas e desvirtuadas sobre a temática e que geraram estereótipos e marcas sensíveis que se opõem ao que pretende a lei? Dito de outro modo: como lidar com um diagnóstico de fragilidade experiencial dos futuros docentes-historiadores para um substantivo aproveitamento da proposta legal?

Tais ideias apresentam duas tensões para o docente interessado em trabalhar com a temática indígena. A primeira, da formação do docente, e a segunda, da especificidade dos saberes indígenas.

Volto à articulação entre memória e história e à diferença entre saber escolar e saber acadêmico, pois mais do que considerar que cada um tem um objetivo e uma produção particular, é considerar a inoperância de certas premissas de um no ambiente do outro. Desse modo, a suposição do excelente curso superior com informações atualizadas sobre história e cultura indígenas não seria suficiente para a formação de um qualificado professor na operação da temática indígena, pois os desafios para lidar com a alteridade e o repertório de práticas/experiências seria exíguo naquele que chega à maioridade sem acesso ao problema. 
Recoloco um necessário fluxo entre formação escolar e formação de professores: os melhores professores serão aqueles que tiverem a oportunidade de - na escola - terem tido acesso a experiências capazes de acionar a identificação, o respeito e o diálogo com alteridades. Na chave do que já foi dito até aqui, mesmo que o conteúdo acionado na antiga sala de aula tenha sido de outra natureza ou com outro conteúdo, o processo do enfrentamento da multivocalidade e da contextualização - quando alunos da escola - seria em si mesmo repertório qualificador desses futuros docentes. Desse modo, a formação de professores deve estar atenta a capacitar seus alunos a reconhecerem as necessidades de seus estudantes (o ouvir) e promoverem experiências capazes de acionar os sentidos para a alteridade. Mais do que conteúdos acerca dos contingentes indígenas ou o saber sobre a pluralidade étnica, os alunos da escola deveriam ter oportunidades experienciais de distanciamento e deslocamento de si, valorizadoras do outro. A citada dimensão experiencial (incorporada da sensibilidade, do afeto, da memória) reveste de potencialidade o aprendizado sobre a temática indígena pois permite, como foi dito antes, que o sujeito lembre e opere com os referenciais construídos, pensando historicamente o hoje.

A especificidade dos saberes indígenas e, nesse caso, sua história e cultura, adensam a problemática. Cito a epígrafe de duas obras indígenas, uma Xacriabá e outra Maxacali:

É importante saber que não é só a escrita em papel que é válida. Sabe por quê? Porque nosso povo já viveu muitos anos sem participar da escrita e diretamente comunicaram uns com os outros através da voz, dos gestos e dos desenhos. (Nelson Xacriabá)

Por que abrir este livro com "Espíritos"?

Porque os espíritos vão ensinar.

Porque aprendemos primeiro com os espíritos, aprendemos as histórias de nossos antepassados.

Porque os espíritos acompanham, ajudam os homens.

Porque todos os tipos de espírito dão força para os Maxacali.

Porque os espíritos são muito fortes, a gente não esquece.

Porque aonde o Maxacali estiver, os espíritos estão junto, dentro do cabelo.

O cabelo, para o Maxacali é muito importante, porque é onde ficam todos os espíritos, yãmiyxop. 
Porque na cura é importante ouvir o canto dos espíritos.

Porque o pajé é o "Pai dos Espíritos".

Porque os espíritos não diferem dos micróbios. (Curar, Maxacali)

A proposição da lei 11.645/2008 deriva de uma política de memória, uma política de inclusão de sujeitos invisibilizados e silenciados por séculos de ações colonizadoras e tutelares (cf. Fernandes, 2012), resultado, portanto, de uma luta, de demandas sociais que foram incorporadas pelo Estado, que assumiu um investimento para diminuição da desclassificação e marginalização decorrentes.

Porém, a inclusão daqueles silenciados não é simplesmente o anúncio de sua existência, mas a consideração de sua diferença, não é a simples introdução de personagens índios na já tradicional cronologia de uma "história do Brasil", mas exige um repensar o que é o Brasil, como foi feita sua história e os parâmetros das alteridades que foram até então deslocadas. Significa um investimento de descentramento historiográfico e pedagógico que não se satisfaz com simples adições de dados no que nós - não indígenas - chamamos cultura ou que definimos como história.

A viabilidade da multivocalidade expõe, por exemplo, os alunos indígenas que frequentavam as salas de aula sem assim serem reconhecidos, bem como o exercício de contextualização exige um deslocamento para a identificação das realidades indígenas bem mais complexas do que o imaginário estereotipado poderia supor, pois há que se lidar, por exemplo, com índios que não nasceram em aldeias e sempre viveram em cidades ou em etnias que perderam a língua materna e que apesar de radicalidades atualizam suas formas de serem índios.

E a imagem estereotipada dos índios nus nas florestas, ou seja, as representações não indígenas mais tradicionais e tidas como "as verdadeiras" não fogem à complexidade, pois na possibilidade da voz, aquilo que se tinha como uno - "o" índio - se apresenta plural e o mínimo esforço de conhecimento expõe que a possibilidade de um diálogo íntegro - que não seja uma nova maquiagem para antigas ações coloniais e tutelares - demanda uma revolução na compreensão não indígena sobre o que é o saber, a história e a cultura. Como afirmou Nelson Xacriabá, há voz, gestos e desenhos, e, caso nós - não indígenas - não tenhamos sensibilidade para interpretá-los, não saberemos lidar com os micróbios. Estaria a universidade preparada? 
Importante. Nada nestas reflexões apaga a multiplicidade de circunstâncias da vida. Todos - alunos e professores - possuem problemas e felicidades que os tornam mais ou menos dispersos, e todos os alertas e cuidados do mundo não excluem nossa humanidade. Desse modo, caro leitor, não imagine que eu esteja monitorando variáveis na suposição de que, atendidas, os resultados serão sempre os esperados. Não, eles nunca o serão. Porque as variáveis mudam, porque a história acontece.

\section{REFERÊNCIAS}

BAKHTIN, Mikhail. Estética da criação verbal. Trad. a partir do francês por Maria Ermantina Galvão G. Pereira, rev. trad. Marina Appenzeller. 2.ed. São Paulo: Martins Fontes, 1997.

BITTENCOURT, Circe Maria Fernandes. Livros didáticos entre textos e imagens. In: . O saber histórico na sala de aula. São Paulo: Contexto, 2001.

BRANDÃO, Carlos Rodrigues. Identidade e etnia: construção da pessoa e resistência cultural. São Paulo: Brasiliense, 1986.

CERRI, Luís Fernando. Ensino de História e consciência histórica. Rio de Janeiro: Ed. FGV, 2011.

CHERVEL, André. História das disciplinas escolares: reflexões sobre um campo de pesquisa. Revista Teoria e Educação, v.2, 1990.

FERNANDES, Eunícia. Do dever de memória ao dever de história: um exercício de deslocamento. In: GONÇALVES, Marcia de A.; ROCHA, Helenice Ap. de B.; REZNIK, Luís; MONTEIRO, Ana M. F. da C. (Org.) Qual o valor da história hoje? Rio de Janeiro: Ed. FGV, 2012.

. Imagens de índios e livros didáticos: uma reflexão sobre representações, sujeitos e cidadania. In: ROCHA, Helenice; REZNIK, Luís; MAGALHÃES, Marcelo (Org.) A história na escola: autores, livros e leituras. Rio de Janeiro: Ed. FGV, 2009.

GOMES, Mércio Pereira. O caminho brasileiro para a cidadania indígena. In: História da cidadania. São Paulo: Contexto, 2013.

GRUPIONI, Luís Donisete Benzi. Livros didáticos e fontes de informações sobre as sociedades indígenas no Brasil. In: SILVA, Aracy Lopes da (Org.) A temática indígena na escola: novos subsídios para professores de $1^{\circ}$ e $2^{\circ}$ graus. Brasília: MEC; Mari; Unesco, 1995.

HARTOG, François. O espelho de Heródoto: ensaio sobre a representação do outro. Belo Horizonte: Ed. UFMG, 1999. 
JULIA, Dominique. Disciplinas escolares: objetivos, ensino e apropriação. In: LOPES, Alice C.; MACEDO, Elizabeth (Org.) Disciplinas e integração curricular: história e políticas. Rio de Janeiro: DP\&A, 2002.

MENESES, Ulpiano T. Bezerra de. Fontes visuais, cultura visual, História visual: balanço provisório, propostas cautelares. Revista Brasileira de História, São Paulo: Anpuh, v.23, n.45, jul. 2003. Disponível em: www.scielo.br/scielo.php?script=sci_ arttext\&pid=S0102-01882003000100002\&lng=es\&nrm=iso\&tlng=pt.

PIMENTEL, Alessandra. A teoria da aprendizagem experiencial como alicerce de estudos sobre desenvolvimento profissional. Estudos de Psicologia, Natal, v.12, n.2, ago. 2007. Disponível em: www.scielo.br/scielo.php?script=sci_ arttext\&pid=S1413-294X2007000200008\&lng=en\&nrm=iso.

RÜSEN, Jörn. Razão histórica. Brasília: Ed. UnB, 2001.

SUBRAHMANYAN, Sanjay. Textures of time: Writing History in South India 16001800. Ranikhet, India: Permanent Black, 2001.

\section{NOTAS}

${ }^{1} \mathrm{O}$ artigo resulta do cruzamento de muitos caminhos, mas teve uma inspiração: Livros didáticos em dimensões materiais e simbólicas, de Antônia Terra de Calazans Fernandes. Agradeço a ela, mais uma vez, por seu trabalho. Devo um agradecimento também ao acolhimento de Júnia Sales Pereira. O texto e alguns dados apresentados só existiram por sua presença - no pleno sentido da palavra - como orientadora de Pós-Doc.

${ }^{2}$ Agradeço ao Departamento de História o apoio na aplicação do questionário e, em especial, a todos os alunos e ex-alunos que se prontificaram a respondê-lo.

${ }^{3}$ Relata a profa. Júnia Sales Pereira ter vivenciado - em experiência de visitas a escolas de educação básica da região metropolitana de Belo Horizonte com estudantes indígenas da Formação Intercultural de Educadores Indígenas, no ano de 2012 - situações em que, mesmo diante de ações pedagógicas nas quais ocorreu trabalho prévio de abordagem de conteúdos de história e cultura indígena com estudantes do ensino fundamental, o contato desses estudantes com os visitantes indígenas de diferentes etnias revelou a permanência de concepções estereotipadas acerca de seus modos de vida como no caso da alimentação, hábitos culturais, relação com o trabalho e moradia. Na oportunidade, a professora constatou a realização de práticas pedagógicas consideradas interessantes para promover a ruptura com noções estereotipadas acerca das culturas e histórias indígenas, como rodas de debate com as crianças, exibição e comentário de documentários da série Os índios e leitura comentada do livro-texto (como no caso de uma escola que adotava, à época, a coleção Fazendo e Compreendendo, de autoria de Lorene dos Santos, Cláudia Ricci e Célio Augusto da Cunha Horta, Editora Saraiva, em que consta abordagem significativa acerca das histórias e culturas indígenas do Brasil). Seu relato expôs que os momentos de encontro das 
crianças com os estudantes indígenas geraram reações em que foram enunciadas dúvidas acerca do canibalismo, por exemplo, além de perguntas sobre se eles moravam na mata, se caçavam e pescavam e por que estavam vestidos com roupas, ou seja, em oposição ao que tinha sido trabalhado na escola e em sintonia com uma regular estereotipia. Para nós, aqui, o fato de as escolas terem se preparado e aos seus alunos (mostrando-se comprometidas com o tema indígena) e ainda assim enfrentarem tal retorno dos alunos expõe que a formação dos cidadãos não se realiza exclusivamente na escola, sendo ela apenas um dos espaços de socialização e formação. Essa observação, porém, a meu critério, não retira da escola uma centralidade nesse processo, haja vista até mesmo sua possibilidade de intervir no resultado do preconceito dos alunos e explorar mais, melhor e sistematicamente o projeto de conhecimento de sociedades indígenas.

${ }^{4}$ Os vazios de informação e os estereótipos são a chave genérica dos livros didáticos para a temática indígena. Cf. BITTENCOURT, 2001; GRUPIONI, 1995.

${ }^{5}$ Que, no caso, mantém a equívoca ideia de ser "um" povo.

${ }^{6}$ Sobre o papel da escola como "liga" ou cimento identitário, bem como sobre as diferenças entre saber escolar e saber acadêmico ver CERRI, 2011.

${ }^{7}$ Acredito com Rüsen que a história como ciência é apenas uma realização particular do pensamento histórico, e recordo os trabalhos de CERVEL, 1990, e JULIA, 2002, para enfatizar a historicidade da disciplina história. Cf. RÜSEN, 2001.

${ }^{8}$ Quanto à afirmação de si através do outro ver BRANDÃO, 1986, e HARTOG, 1999. Sobre o conceito de intersubjetividade dentro desse processo ver BAKHTIN, 1997.

Artigo recebido em 24 de setembro de 2014. Aprovado em 23 de outubro de 2014. 